\title{
GRADED PHOTONIC CRYSTALS FOR GRADED INDEX
}

\section{LENS}

\author{
F. Gaufillet and É. Akmansoy
}

November 17, 2011

\begin{abstract}
A graded index lens made from graded 2D photonic crystal has been designed by the means of the Finite Difference Time Domain (FDTD) method. The gradient of index has been obtained by varying the filling factor of a flat slab of photonic crystal in the direction perpendicular to that of the propagation of the electromagnetic field. This gradient has been designed in such a way that the flat slab focuses a plane wave. As only a few layers are necessary, graded photonic crystals show their ability to efficiently control the propagation of light and may apply to various photonic devices, from the microwave range to the optical domain.
\end{abstract}

